\title{
A clinical morphologic study of the $\mathrm{C} 2$ pedicle and isthmus
}

\author{
Feng Yuan $\cdot$ Hui-Lin Yang $\cdot$ Kai-Jin Guo $\cdot$ \\ Jiang-Shan Li $\cdot$ Kai Xu $\cdot$ Zhi-Ming Zhang • \\ Tian-Si Tang
}

Received: 2 May 2011/Revised: 15 May 2012/ Accepted: 18 June 2012/Published online: 14 August 2012

(C) Springer-Verlag 2012

\begin{abstract}
Purpose This anatomic, radiographic study investigated locational differences in the $\mathrm{C} 2$ pedicle and isthmus [pediculoisthmic component (PIC)] and characterized its narrowest section for clinical application in posterior $\mathrm{C} 2$ screw fixation.

Methods Structures surrounding the transverse foramina of 30 dry C2s and $10 \mathrm{C} 3 \mathrm{~s}$ were compared morphologically. Spinal CT scans of 32 Chinese adults were subjected to volume rendering and multiplanar reconstruction to identify the narrowest C2 PIC, and correlative parameters were measured and analyzed.

Results Inferior $\mathrm{C} 2$ and $\mathrm{C} 3$ structures were morphologically similar. In superior view, the $\mathrm{C} 2$ superior facets lay on the transverse foramen and the upper portion between superior and inferior facets was flat (average mediolateral angle, $11.1^{\circ} \pm 2.4^{\circ}$ ). In inferior view, the posteroinferomedial portion of the $\mathrm{C} 2$ transverse foramen displayed a partially tubular structure (average mediolateral angle of projection, $42.6^{\circ} \pm 4.9^{\circ}$ ). Average height and width were 11.6 and $6.9 \mathrm{~mm}$. The inner medullary cavity was elliptical and the middle site of endosteal diameter was $3.3 \pm 1.9 \mathrm{~mm}$.
\end{abstract}

F. Yuan $(\bowtie) \cdot$ K.-J. Guo

Department of Orthopedics,

Affiliated Hospital of Xuzhou Medical College,

Xuzhou City 221000, China

e-mail: cnyuanfeng@hotmail.com

H.-L. Yang · Z.-M. Zhang · T.-S. Tang

Department of Orthopedics,

First Affiliated Hospital of Suzhou University,

Suzhou 215000, China

J.-S. Li $\cdot$ K. Xu

Department of Radiology,

Affiliated Hospital of Xuzhou Medical College,

Xuzhou City 221000, China
Medial internal cortical bone was significantly thicker than lateral bone $(P<0.01)$.

Conclusions The PIC is located between superior and inferior $\mathrm{C} 2$ facets. The superior flat area is the isthmus and the inferomedial area connecting the inferior facet and vertebral body is the pedicle. The pedicle is partially tubular and projects posteromedially to the transverse foramen. The narrowest PIC section is the narrowest point of the $\mathrm{C} 2$ pedicle. Considering its thin lateral cortical bone, medial and superior pedicle screw placement and preoperative $\mathrm{CT}$ reconstruction are recommended.

Keywords C2 $\cdot$ Axis $\cdot$ Pedicle $\cdot$ Isthmus . Reformatted CT

\section{Introduction}

Occipitocervical and atlantoaxial instability are commonly caused by trauma, tumor presence, congenital malformation, or inflammatory diseases, and can be treated by reduction and stabilization of the occipitocervical junction to prevent neurologic damage and vessel compression. In recent years, techniques for short-segment fixation of occipitocervical and atlantoaxial instability have focused on the second cervical vertebra $(\mathrm{C} 2)$ because of its biomechanical prominence [1-4]. For example, Magerl and Seemann [3] first described the transarticular screw fixation technique in 1986, and Harms and Melcher [4] introduced the bilateral insertion of polyaxial-head screws into the lateral mass of the first cervical vertebra $(\mathrm{C} 1)$ and the pedicle of the $\mathrm{C} 2$ for $\mathrm{C} 1-\mathrm{C} 2$ fixation. These techniques are technically demanding and pose risk of injury to the vertebral artery (VA), especially in cases of structural disfigurement [5-9]. Wright [10] introduced the use of bilateral 
laminar screws crossing the $\mathrm{C} 2$, which allowed for safer, rigid $\mathrm{C} 2$ fixation without VA injury. However, this technique depends on the integrity of the $\mathrm{C} 2$ lamina and thus cannot replace the transarticular screw or $\mathrm{C} 2$ pedicle screw techniques.

The existing literature has presented confusing definitions of the $\mathrm{C} 2$ pedicle and isthmus because the $\mathrm{C} 2$ is considered to be a transitional vertebra [11]. Different views of this anatomy will result in the collection of different data, which may have negative clinical effects. Thus, the anatomic location of the pediculoisthmic component (PIC) must be defined precisely. Furthermore, the narrowest portion of the $\mathrm{C} 2 \mathrm{PIC}$ and the characteristics of its internal structure remain unclear. In this study, the association between the $\mathrm{C} 2$ pedicle and isthmus was investigated by observation and comparison of vertebral specimens. The narrowest section of the C2 PIC was identified using computed tomography (CT) with multiplanar reconstruction, and the anatomic parameters of this section were measured through CT examination. The purpose of this study was to clarify the characteristics of the pedicle and isthmus structures to improve the safety and accuracy of posterior $\mathrm{C} 2$ screw fixation.
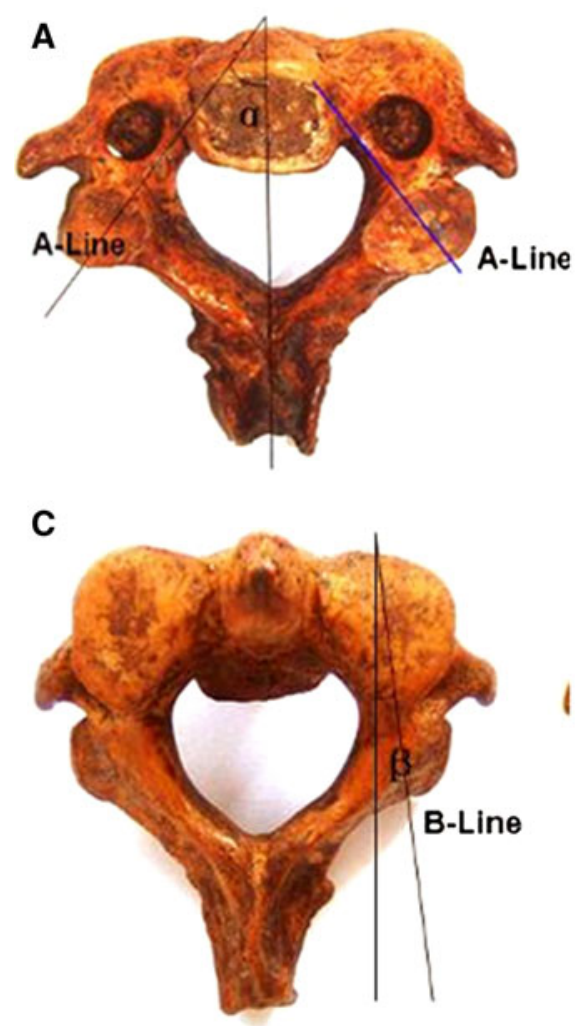

\section{Materials and methods}

Morphologic analysis

Thirty intact, dry C2 vertebrae and 10 intact, dry C3 vertebrae from Chinese adults were obtained for the external morphologic study. Observation was focused on the structures surrounding the transverse foramina in $\mathrm{C} 2$ and C3 specimens. The structures were compared morphologically between vertebrae, including the portions between the superior and inferior facets in the sagittal aspect, the portions between the superior facets and the dens/vertebral body in the coronal aspect, and the portions between the superior/inferior facets and dens/vertebral body in the horizontal aspect.

In an inferior view of the $\mathrm{C} 2$, the portion between the inferior facets/transverse foramen and the vertebral body was a partially tubiform structure. The axis of this structure was designated line A and contributed to angle $\alpha$ with the sagittal axis of the $\mathrm{C} 2$. Angle $\beta$ was composed of the axis of the structure between the superior and inferior facets (line B) and the sagittal axis of the $\mathrm{C} 2$. Angles $\alpha$ and $\beta$ were measured and compared with those of C3 (Fig. 1).

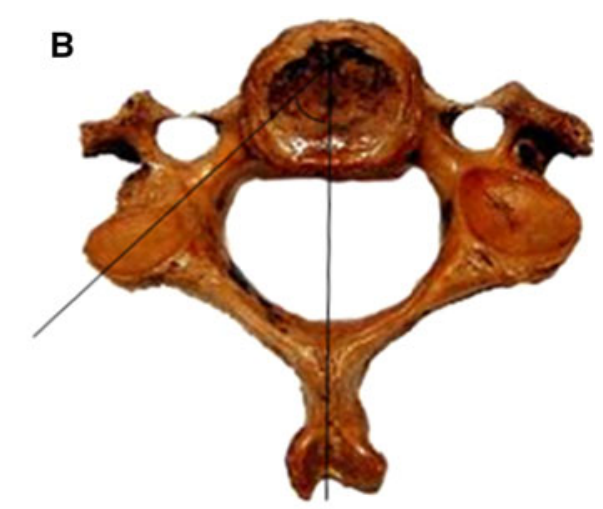

D

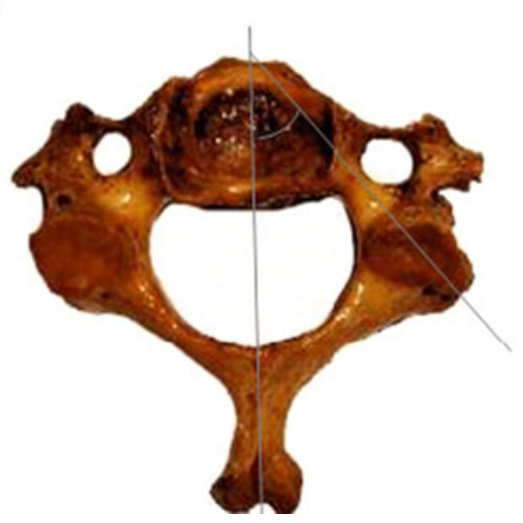

Fig. 1 a Inferior view of the $\mathrm{C} 2$; angle $\alpha$ is composed of line $A$ and the sagittal axis of the $\mathrm{C} 2$. $\mathbf{b}$ Inferior view of the C3. c Superior view of the $\mathrm{C} 2$; angle $\beta$ is composed of line $B$ and the sagittal axis of the $\mathrm{C} 2$. d Superior view of the $\mathrm{C} 3$ 
Determination and measurement of the narrowest section of the $\mathrm{C} 2$ on $\mathrm{CT}$ images

Helical CT scans of 32 patients ( 24 men, 8 women; mean age, $51.2 \pm 21.5$ years; range 17-75 years) were collected for this study. All patients had undergone CT examinations (LightSpeed 16 Pro spiral CT; slice thickness, $1 \mathrm{~mm}$; GE company) including visualization of the complete atlantoaxial segment for the investigation of head and neck trauma and carotid artery disease. Following a reconstruction interval of $0.3 \mathrm{~mm}$, all files were reloaded in workstation AD 4.12, and volume rendering and multiplanar reconstruction were performed to identify the narrowest portion of the PIC.

Measurements were obtained as follows: first, the introversional central axis (line 1) of the PIC was drawn on each plain CT image (Fig. 2a). Then, the introversional sagittal section was obtained along line 1 (Fig. 2b) and a central line (line 2) was drawn on this section (Fig. 2c). By performing the software's "undo scalpe" operation in toolbar, the inferior-superior versional section was obtained along line 2, and line 3 was drawn vertically at the narrowest point of this inferior-superior versional section (Fig. 2d). By performing the "undo scalpe" operation again, the vertical section of the oblique axial plane was obtained along line 3, and the vertical section was considered to be the narrowest portion of the C2 PIC (Fig. 2e-h).
The values of correlative items were measured with digital calipers on CT images with multiplanar reconstruction.

The parameters selected for the measurement of the narrowest vertical section are shown in Fig. 3; these include the heights of the narrowest section (AD) and medullary cavity (BC), thicknesses of the superior (AB) and inferior (CD) cortical bone, middle widths of the narrowest section (EH) and medullary cavity (FG), thicknesses of the middle lateral (EF) and media $(\mathrm{GH})$ cortical bone, and the thickness of the superomedial cortical bone (IJ), which is of the same level as the superior margin of the transverse foramen. All parameters were measured by the same radiologist.

The parameters were analyzed with SAS software (ver. 6.12; SAS Institute, Cary, NC, USA). Statistical significance was set at $P<0.05$.

\section{Results}

Morphologic analysis

In a superior view of the $\mathrm{C} 2$, the superior facets lay on the transverse foramen. The upper portion between the superior and inferior facets was flat, with an average width of $7.5 \pm 2.3 \mathrm{~mm}$ (range $3.5-12.7 \mathrm{~mm}$ ). The average value of
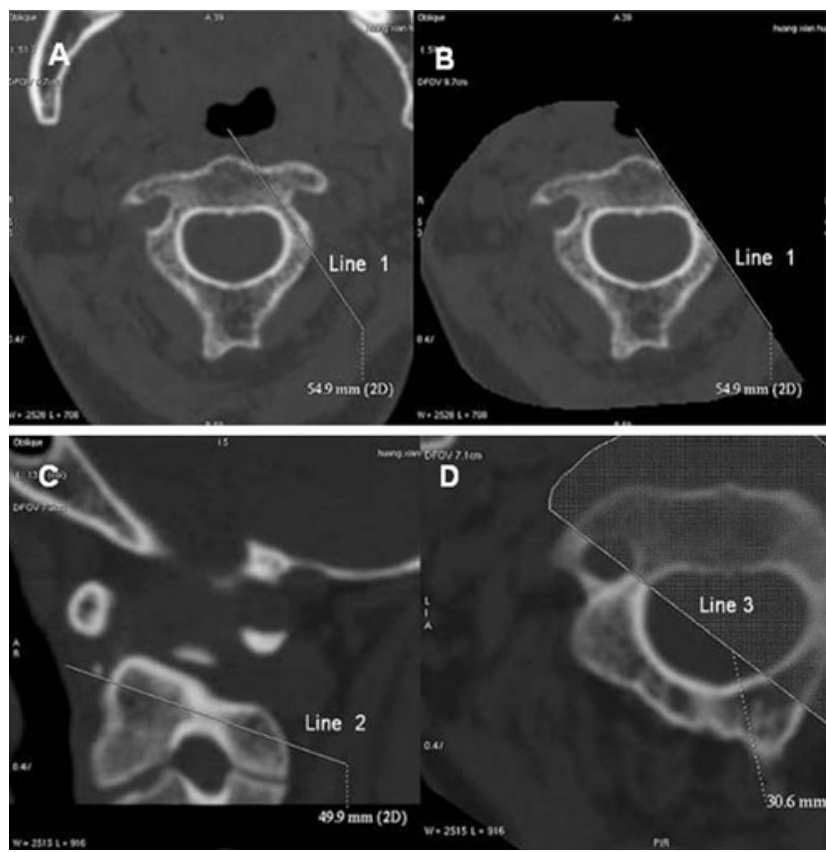

Fig. 2 a Determination of the pediculoisthmic axis (line 1). b A mediolateral longitudinal section was defined along line 1. c The central line (line 2) was defined on the mediolateral sagittal section. d After performing the "undo scalpe" operation in toolbar, the inferior-superior versional section was obtained along line 2 and line 3 was drawn vertically at the narrowest location on this section.

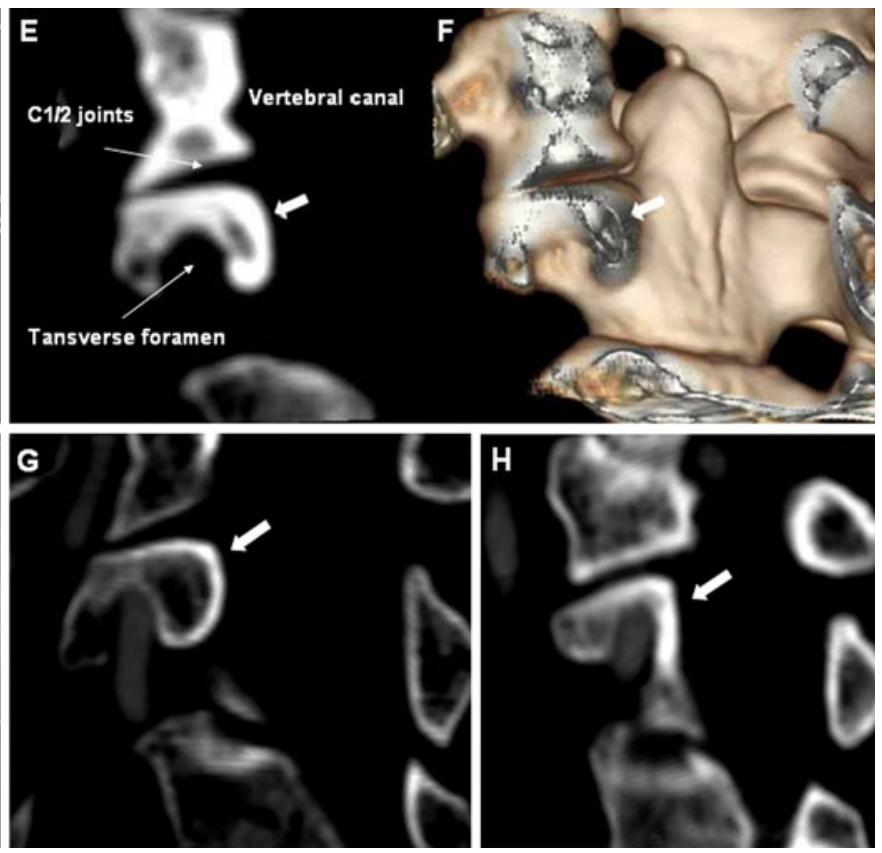

e, $\mathbf{f}$ The narrowest vertical section of the pediculoisthmic component was determined along line 3 after performing "undo scalpe" (large white arrows on two-dimensional and three-dimensional images). $\mathbf{g}, \mathbf{h}$ The other two kinds of contour at the narrowest vertical section (large white arrows) 


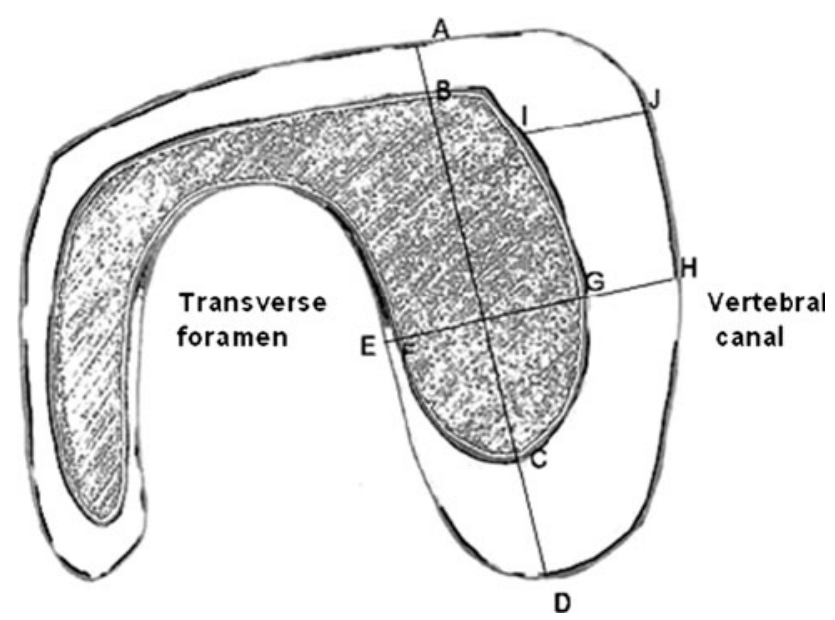

Fig. 3 Measurement of the narrowest vertical section of the pediculoisthmic component

angle $\beta$ was $11.1^{\circ} \pm 2.4^{\circ}$ (range $7.0^{\circ}-15.0^{\circ}$ ). In an inferior view of the $\mathrm{C} 2$, Portion posteroinferomedial to the transverse foramen displayed two kinds of shape: a partially tubular structure in $88.3 \%$ of cases (53 sides), and a thin paries in $11.7 \%$ of cases (7 sides; Fig. 4). There are Two C2 specimens displayed bilateral thin paries (Fig. 5). The average width of the portion was $3.9 \pm 1.4 \mathrm{~mm}$ (range $0.6-7.8 \mathrm{~mm}$ ). The average value of angle $\alpha$ was $42.6^{\circ} \pm$ $4.9^{\circ}$ (range $32^{\circ}-50.5^{\circ}$ ). Differences in angles $\alpha$ and $\beta$ between the left and right sides were not statistically significant $\left(P_{\alpha}=0.3357, P_{\beta}=0.8686\right.$; Table 1$)$. The average convergence angle in $\mathrm{C} 3$ specimens was $43.2^{\circ}$.

The exterior appearance of the inferior $\mathrm{C} 2$ structure was more similar to the anatomy of the $\mathrm{C} 3$ than to that of the superior $\mathrm{C} 2$ structure; in other words, the structures surrounding the entrance to the $\mathrm{C} 2$ transverse foramen were more similar to those of the $\mathrm{C} 3$, and the partially tubiform structure of the inferior $\mathrm{C} 2$ was similar to the $\mathrm{C} 3$ pedicle.

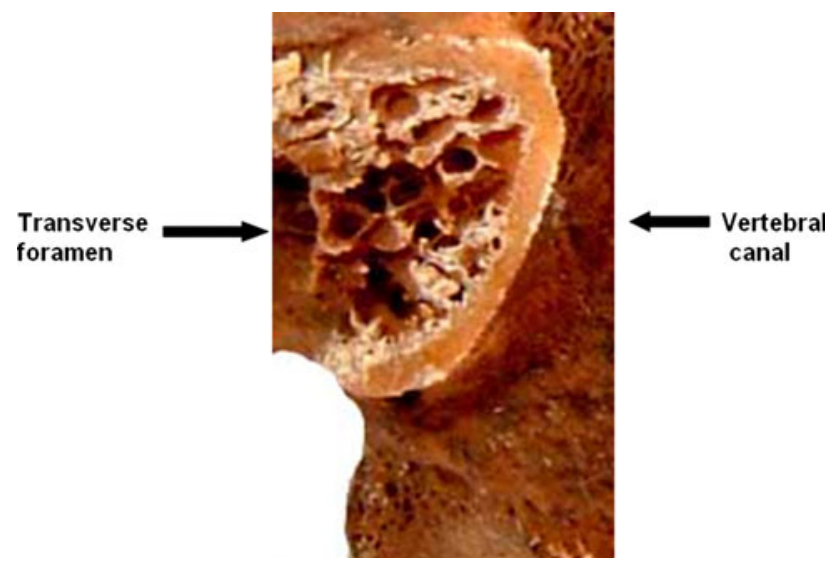

Fig. 4 The narrowest section of the PIC in a dry C2 specimen
Radiographic analysis

The typical morphology of the narrowest PIC section was a fishhook shape, regardless of the morphology of the cortical bone of the superior articular process. The internal morphology of the medullary cavity was mostly elliptical (Figs. 2, 3, 4). The medial cortical bone was significantly thicker than the lateral, and the inferior cortical bone was significantly thicker than the superior (both $P<0.01$ ).

Among the 64 examples of the narrowest PIC section in the sample, two cases were statistically rejected because the narrowest section looked like trips without a medullary cavity (Fig. 2h). Differences in parameters between the left and right sides were not significant $(P>0.05)$, except the thickness of superomedial cortical bone $\left(P_{\mathrm{IJ}}=0.027\right)$. The average height $(\mathrm{AD})$ and width $(\mathrm{EH})$ of the narrowest section were 11.6 and $6.9 \mathrm{~mm}$, respectively, and the central endosteal diameter was $3.3 \pm 1.9 \mathrm{~mm}$. The middle medial cortical bone $(\mathrm{GH})$ was significantly thicker than the lateral (EF) cortical bone $(P<0.01)$ and significantly thinner than the superomedial cortical bone (IJ; $P<0.01$ ). The superior cortical bone $(\mathrm{AB})$ was significantly thinner than the inferior cortical bone $(\mathrm{CD} ; P<0.01$; Table 2).

\section{Discussion}

A typical pedicle connects the vertebral body with the posterior elements. The isthmus (pars interarticularis), located between the superior and inferior articular processes, is the narrowest portion of the neural arch. In a typical subaxial vertebra, the transverse foramen is adjacent to the lateral side of the vertebral body and the anterior and posterior tubercles of the transverse process are lateral to the transverse foramen. The anterior tubercle evolved from a rib structure, whereas the posterior tubercle is the real transverse process. The superior and inferior articular processes blend with the lamina. Thus, no clinical term describes the isthmus in subaxial vertebrae.

As a transitional vertebra, the $\mathrm{C} 2$ has a unique structure. Most orthopedic and neurosurgical literature has presented confusing definitions of the $\mathrm{C} 2$ pedicle and isthmus. Although the terms are used frequently and interchangeably, the pars and pedicle of the $\mathrm{C} 2$ are two distinct structures [11]. Because different views of this anatomy will yield different research data, the anatomic locations of these structures must be defined precisely. Borne et al. [12] defined the $\mathrm{C} 2$ pedicle as the narrower portion joining the vertebral body/odontoid base complex to the superior articular process and the isthmus as the portion located between the superior and inferior facets. In contrast, Yarbrough et al. [13] referred to the portion between the superior and inferior facets as the pedicle, Ebraheim et al. [14] 
Fig. 5 The portion project posteromedially to the transverse foramen displaying unilateral (a) or bilateral (b) thin paries
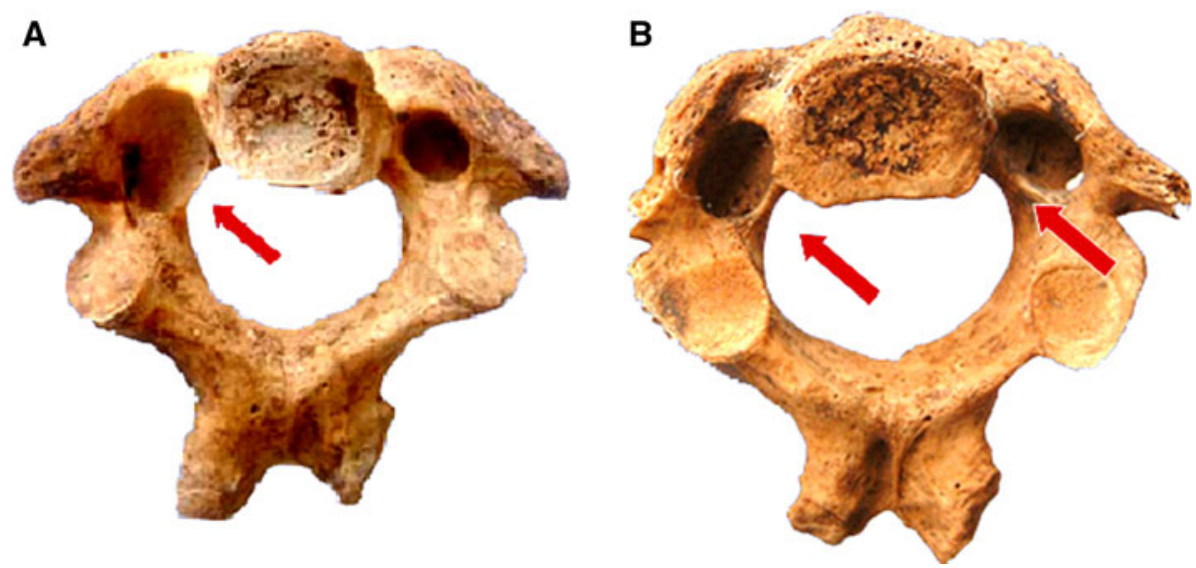

Table 1 Angles $\alpha$ and $\beta$ in the $\mathrm{C} 2$

\begin{tabular}{lccccccc}
\hline Side & $\alpha\left(^{\circ}\right)$ & & & & $\beta\left(^{\circ}\right)$ & & \\
\cline { 2 - 3 } & Mean & SD & Min-max & & Mean & SD & Min-max \\
\hline L & 43.4 & 4.6 & $32.0-50.5$ & & 11.5 & 2.4 & $7.5-15.0$ \\
R & 41.8 & 5.3 & $34.0-50.5$ & & 10.6 & 2.4 & $7.0-14.5$ \\
Both & 42.6 & 4.9 & $32.0-50.5$ & & 11.1 & 2.4 & $7.0-15.0$ \\
\hline
\end{tabular}

Left versus right: $P_{\alpha}=0.3357, P_{\beta}=0.8686$

$S D$ standard deviation

defined the pedicle as the portion beneath the superior facet and anteromedial to the transverse foramen, and Naderi et al. [15] used the term pedicle to refer to the structure beneath the isthmus connecting the mass lateral to the inferior facet with the vertebral body. Like Borne et al. [12], Ebraheim et al. [14] defined the isthmus as the narrower portion between the superior and inferior facets and Naderi et al. [15] reported that the isthmus was located between the superior and inferior articular processes. Naderi et al. [15] suggested the use of the term PIC to refer to the $\mathrm{C} 2$ isthmus and pedicle.

The results of the present study support the terminology used by Naderi et al. [15]. We disagree with the definition of the $\mathrm{C} 2$ isthmus as the portion between the superior and inferior facets. The inferior structure of the $\mathrm{C} 2$ was very similar to that of the $\mathrm{C} 3$, and the mean axial angle $\left(\alpha, 42.6^{\circ}\right)$ approached those observed in the lower cervical vertebrae [16-19]. The superior structure of the $\mathrm{C} 2$ differed markedly from that of the $\mathrm{C} 3$; the mean angle $\beta$ was $11.1^{\circ}$ and the superior facets blend with the anterior vertebral body in the $\mathrm{C} 2$. Assuming that the superior facets of the $\mathrm{C} 3$ were dragged to the site of the uncinate process on the same side, similar structures would be present around the transverse foramina of the $\mathrm{C} 2$ and $\mathrm{C} 3$ (Fig. 6). We believe that the superior facets of the $\mathrm{C} 2$ moved to a similar site as the $\mathrm{C} 3$ uncinate process to match the position of the $\mathrm{C} 1$
Table 2 Anatomic parameters of the narrowest site of the pediculoisthmic component

\begin{tabular}{|c|c|c|c|}
\hline Item & Side & Mean \pm SD $(\operatorname{Min}-\max )(\mathrm{mm})$ & $P$ \\
\hline \multirow[t]{3}{*}{$\mathrm{AD}$} & $\mathrm{L}$ & $11.9 \pm 1.26(9.6-14.7)$ & 0.072 \\
\hline & $\mathrm{R}$ & $11.4 \pm 0.93(9.2-12.8)$ & \\
\hline & Both & $11.6 \pm 1.34(9.2-14.7)$ & \\
\hline \multirow[t]{3}{*}{$\mathrm{BC}$} & $\mathrm{L}$ & $5.5 \pm 1.58(2.6-10.4)$ & 0.386 \\
\hline & $\mathrm{R}$ & $5.9 \pm 1.6(3.6-8.6)$ & \\
\hline & Both & $5.8 \pm 1.79(2.6-10.4)$ & \\
\hline \multirow[t]{3}{*}{$\mathrm{AB}$} & $\mathrm{L}$ & $2.8 \pm 0.78(1.4-3.8)$ & 0.436 \\
\hline & $\mathrm{R}$ & $2.7 \pm 0.75(1.4-3.8)$ & \\
\hline & Both & $2.7 \pm 0.76(1.4-3.8)$ & \\
\hline \multirow[t]{3}{*}{$\mathrm{CD}$} & $\mathrm{L}$ & $3.3 \pm 0.88(2.0-5.3)$ & 0.136 \\
\hline & $\mathrm{R}$ & $3.0 \pm 0.95(1.7-4.7)$ & \\
\hline & Both & $3.2 \pm 0.92(1.7-5.3)$ & \\
\hline \multirow[t]{3}{*}{$\mathrm{EH}$} & $\mathrm{L}$ & $6.9 \pm 2.55(2.7-11.9)$ & 0.659 \\
\hline & $\mathrm{R}$ & $6.7 \pm 1.57(5.2-10.0)$ & \\
\hline & Both & $6.9 \pm 2.18(2.7-11.9)$ & \\
\hline \multirow[t]{3}{*}{ FG } & $\mathrm{L}$ & $3.5 \pm 2.29(0.7-7.2)$ & 0.198 \\
\hline & $\mathrm{R}$ & $3.0 \pm 1.25(1.1-5.4)$ & \\
\hline & Both & $3.3 \pm 1.89(0.7-7.2)$ & \\
\hline \multirow[t]{3}{*}{ GH } & $\mathrm{L}$ & $2.4 \pm 0.58(1.5-4.1)$ & 0.851 \\
\hline & $\mathrm{R}$ & $2.4 \pm 0.46(1.8-3.7)$ & \\
\hline & Both & $2.4 \pm 0.53(1.5-4.1)$ & \\
\hline \multirow[t]{3}{*}{$\mathrm{EF}$} & $\mathrm{L}$ & $1.1 \pm 0.59(0.2-2.4)$ & 0.134 \\
\hline & $\mathrm{R}$ & $1.4 \pm 0.88(0.3-3.1)$ & \\
\hline & Both & $1.2 \pm 0.76(0.2-3.1)$ & \\
\hline \multirow[t]{3}{*}{ IJ } & $\mathrm{L}$ & $2.9 \pm 0.86(2.2-4.7)$ & 0.027 \\
\hline & $\mathrm{R}$ & $2.5 \pm 0.81(1.7-3.7)$ & \\
\hline & Both & $2.7 \pm 0.74(1.7-4.7)$ & \\
\hline
\end{tabular}

$S D$ standard deviation, $L$ left, $R$ right, $A D$ height of the narrowest section, $B C$ height of medullary cavity, $A B$ thickness of superior cortical bone, $C D$ thickness of inferior cortical bone, $E H$ central width of the narrowest section, $F G$ central width of the medullary cavity, $E F$ thickness of the central external cortical bone, $G H$ thickness of central internal cortical bone, $I J$ thickness of superomedial cortical bone 
A

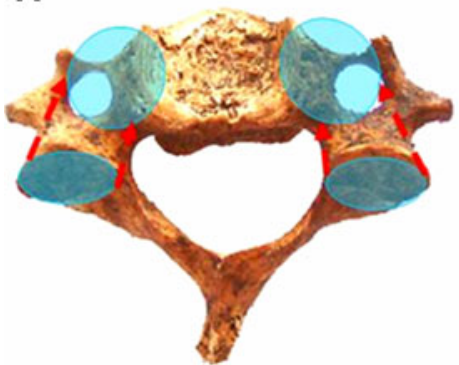

B

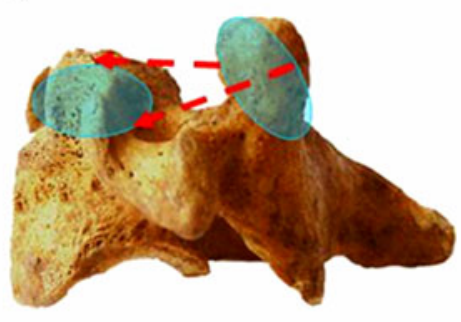

C

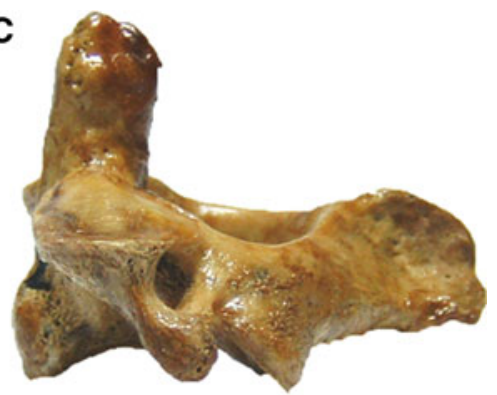

Fig. 6 The superior articular process of the $\mathrm{C} 3$ was assumed to be drawn to the location of the vertebral process (a), in which case similar structures would be seen around the transverse foramina of the C3 (b) and C2 (c)

inferior facets during evolution. This process stretched the upper portion between the superior and inferior facets into a flat structure, which should be called the $\mathrm{C} 2$ isthmus or pars interarticularis. The isthmus drapes over the $\mathrm{C} 2$ pedicle, which can be seen on the inferior aspect of the vertebra. The pedicle is a partially tubular structure beneath the superior facet and isthmus and posteromedial to the transverse foramen. Therefore, all the portions between the superior and inferior facets should be defined as the PIC.

In this study, we found that the narrowest section of the PIC consisted of the superior facet, not the portion between the superior and inferior facets. Thus, the narrowest section of the PIC should be the narrowest site on the $\mathrm{C} 2$ pedicle. Based on these results, we think that the entry point for screw fixation is located in the craniomedial quadrant of the dorsal part of the $\mathrm{C} 2$ inferior facet and the trace pass through the axis of the isthmus and toward the undersurface of the superior facet (Harms technique). We call this the "C2 isthmic screw technique." In another method, which we call the " $\mathrm{C} 2$ pedicle screw technique" or " $\mathrm{C} 2$ PIC screw technique," the screw entry point is located at the intersection between the central vertical line and the cranial surface of the $\mathrm{C} 2$ inferior facet, and the exit point is located at the intersection between the odontoid part and the undersurface of the superior facet.

Not all pedicles in our sample had a partially tubular structure; a minority $(11.7 \%)$ displayed thin paries due to anatomic variation or the presence of a large transverse foramen grooved by the VA. Given this unique anatomy, the placement of a transarticular or pedicle screw risks damage to the VA. Therefore, preoperative CT planning is mandatory to determine the $\mathrm{C} 2$ pedicle anatomy in each patient and design an appropriate screw trajectory $[11,20]$.

Because of the inferior-superior angle of the PIC, visualization of the narrowest section of the $\mathrm{C} 2$ pedicle is difficult on standard CT scans. In this study we measured the narrowest section, which is perpendicular to the PIC axis, using CT with multiplanar reconstruction. We found that the medial cortical bone $(\mathrm{GH})$ was significantly thicker than the lateral cortical bone (EF), but thinner than the superomedial cortical bone. The thin lateral cortical bone could easily be breached during $\mathrm{C} 2$ pedicle or transarticular screw placement without any free-hand feeling, even for experienced surgeons (Fig. 4). Manual palpation is thus very important during pedicle screw placement. Sciubba et al. [21] reported $15(15 \%)$ breaches among 100 consecutive free-hand screw placements, $12(80 \%)$ of which were lateral. Alosh et al. [20] reported the detection of $43(25.3 \%)$ breaches on postoperative CT scans of 93 patients in which a total of $170 \mathrm{C} 2$ pedicle screws were placed. A pedicle diameter $<6 \mathrm{~mm}$ was associated with a nearly twofold increase in the risk of cortical breach. In the present study, the average height and width of the narrowest section were 11.6 and $6.9 \mathrm{~mm}$, and the thicknesses of the inferior and superior cortical bone were 3.2 and $2.7 \mathrm{~mm}$. Thus, pedicle screw placement at an inferior-superior angle provides more space and a larger range of safe trajectory than placement at a lateral-medial angle. We plant to investigate the safe range of this angle in a subsequent study.

Given the potential for a "high-riding" VA or an anomalous VA course, posterior atlantoaxial transarticular and pedicle screw fixation risk VA injury [9]. Reported rates of VA injury range from 2 to $5 \%$ [7, 22]. Studies have documented that $10-23 \%$ of patients may not be suitable candidates for atlantoaxial transarticular or pedicle screw fixation on at least one side [23-25]. In the present study of dry specimens, $11.7 \%$ of $\mathrm{C} 2$ pedicles were unsuitable for pedicle screw placement.

Misenhimer et al. [26] reported that plastic deformation of the pedicle preceded pedicle fracture or cutout when the screw thread diameter was larger than the endosteal diameter or within $80 \%$ of the outer cortical diameter. In our study, the central endosteal and outer cortical diameters of the narrowest section were $3.3 \pm 1.9$ and $6.9 \pm 2.2 \mathrm{~mm}$, respectively. Thus, the use of a $3.5-\mathrm{mm}$ screw is optimal in the $\mathrm{C} 2$ pedicle. Diameters of 3,4 , or $4.5 \mathrm{~mm}$ may be considered, but their use must depend on preoperative three-dimensional evaluation [11]. 


\section{Conclusions}

The PIC is the $\mathrm{C} 2$ structure between the superior and inferior articular processes; the superior flat aspect is the isthmus, which drapes over the pedicle. The pedicle is a partially tubular structure projecting posteromedially to the transverse foramen. The narrowest section of the PIC is the narrowest point on the $\mathrm{C} 2$ pedicle. Given the thin lateral cortical bone at this point, more medial and superior placement of pediculoisthmic screws is recommended, and preoperative $\mathrm{CT}$ reconstruction is mandatory to determine each patient's $\mathrm{C} 2$ pedicle anatomy and design an appropriate screw trajectory.

Conflict of interest None.

\section{References}

1. Kuroki H, Rengachary SS, Goel VK et al (2005) Biomechanical comparison of two stabilization techniques of the atlantoaxial joints: transarticular screw fixation versus screw and rod fixation. Neurosurgery 56(S1):151-159

2. Melcher RP, Puttlitz CM, Kleinstueck FS et al (2002) Biomechanical testing of posterior atlantoaxial fixation techniques. Spine 15(27):2435-2440

3. Magerl F, Seeman PS (1987) Stable posterior fusion of the atlas and axis by transarticular screw fixation. In: Kehr P (ed) Weidner A: Cervical Spine. Springer-Verlag, Vienna, pp 322-327

4. Harms J, Melcher RP (2001) Posterior C1-C2 fusion with polyaxial screw and rod fixation. Spine 26:2467-2471

5. Bloch O, Holly LT, Park J et al (2001) Effect of frameless stereotaxy on the accuracy of $\mathrm{C} 1-\mathrm{C} 2$ transarticular screw placement. J Neurosurg 95:74-79

6. Goel A, Gupta S (1999) Vertebral artery injury with transarticular screws. J Nurosurg 90:376-377

7. Neo M, Matsushita M, Iwashita Y et al (2003) Atlantoaxial transarticular screw fixation for a High-Riding vertebral artery. Spine 28:666-670

8. Sakamoto T, Neo M, Nakamura T (2004) Transpedicular screw placement evaluated by axial computed tomography of the cervical pedicle. Spine 29:2510-2514

9. Yoshida M, Neo M, Fujibayashi S et al (2006) Comparison of the anatomical risk for vertebral artery injury associated with the C2-pedicle screw and atlantoaxial transarticular screw. Spine 31:E513-E517

10. Wright NM (2004) Posterior C2 fixation using bilateral, crossing C2 laminar screws: case series and technical note. J Spinal Disord Tech 17:158-162
11. Smith ZA, Bistazzoni S, Onibokun A et al (2010) Anatomical considerations for subaxial (C2) pedicle screw placement: a radiographic study with computed tomography in 93 patients. J Spinal Disord Tech 23:176-179

12. Borne GM, Bedou GL, Pinaudeau M (1984) Treatment of pedicular fractures of the axis. A clinical study and screw fixation technique. J Neurosurg 60:88-93

13. Yarbrough BE, Hendey GW (1990) Hangman's fracture resulting from improper seat belt use. South Med J 83:843-845

14. Ebraheim NA, Fow J, Xu R et al (2001) The Location of the Pedicle and Pars Interarticularis in the Axis. Spine 26:E34-E37

15. Naderi S, Arman C, Guvencer M et al (2004) An anatomical study of the C-2 pedicle. J Neurosurg 3:303-310

16. Reinhold M, Bach C, Audigé L et al (2008) Comparison of two novel fluoroscopy-based stereotactic methods for cervical pedicle screw placement and review of the literature. Eur Spine J 17(4):564-575

17. Reinhold M, Magerl F, Rieger M, Blauth M (2007) Cervical pedicle screw placement: feasibility and accuracy of two new insertion techniques based on morphometric data. Eur Spine J $16(1): 47-56$

18. Onibokun A, Khoo LT, Bistazzoni S, Chen NF, Sassi M (2009) Anatomical considerations for cervical pedicle screw insertion: the use of multiplanar computerized tomography measurements in 122 consecutive clinical cases. Spine J 9:729-734

19. Ebraheim NA, Xu R, Knight T, Yeasting RA (1997) Morphometric evaluation of lower cervical pedicle and its projection. Spine 22(1):1-6

20. Alosh H, Parker SL, McGirt MJ et al (2010) Preoperative radiographic factors and surgeon experience are associated with cortical breach of $\mathrm{C} 2$ pedicle screws. J Spinal Disord Tech 23:9-14

21. Sciubba DM, Noggle JC, Vellimana AK et al (2009) Radiographic and clinical evaluation of free-hand placement of $\mathrm{C}-2$ pedicle screws. J Neurosurg (S) 11:15-22

22. Fuji T, Oda T, Kato Y, Fujita S, Tanaka M (2000) Accuracy of atlantoaxial transarticular screw insertion. Spine 25:1760-1764

23. Paramore CG, Dickman CA, Sonntag VK (1996) The anatomical suitability of the $\mathrm{C} 1-2$ complex for transarticular screw fixation. J Neurosurg 85:221-224

24. Mandel IM, Kambach BJ, Petersilge CA et al (2000) Morphologic considerations of $\mathrm{C} 2$ isthmus dimensions for the placement of transarticular screws. Spine 25(12):1542-1547

25. Kuroki H, Rengachary SS, Goel VK et al (2005) Biomechanical comparison of two stabilization techniques of the atlantoaxial joints: transarticular screw fixation versus screw and rod fixation. Neurosurgery 56(S1):151-159

26. Misenhimer GR, Peek RD, Wiltse LL et al (1989) Anatomic analysis of pedicle cortical and cancellous diameter as related to screw size. Spine 14:367-372 